\title{
Dissecting superior cerebellar artery aneurysm: spontaneous resolution in a long-term follow-up
}

Aneurisma dissecante de artéria cerebelar superior: resolução espontânea após seguimento de controle

Marcos Vinicius Tadao Fujino ${ }^{1}$, Rogério Iquizli', Thiago Abud', Carlos Eduardo Baccin', Gisele Sampaio Silva ${ }^{1,2}$, Orlando G. Barsottini, ${ }^{1,2}$, José Luiz Pedroso ${ }^{1,2}$

A 48-year-old woman presented with sudden posterior neck pain 12 hours before admission. Past medical history was unremarkable. Neurological examination was normal. A brain CT scan and cerebrospinal fluid were normal. A MRI angiography (MRA) and digital angiography confirmed a dissecting superior cerebellar artery (SCA) aneurysm (Figure 1). We decided for noninvasive therapy. Six months later, the MRA showed complete resolution (Figure 2).
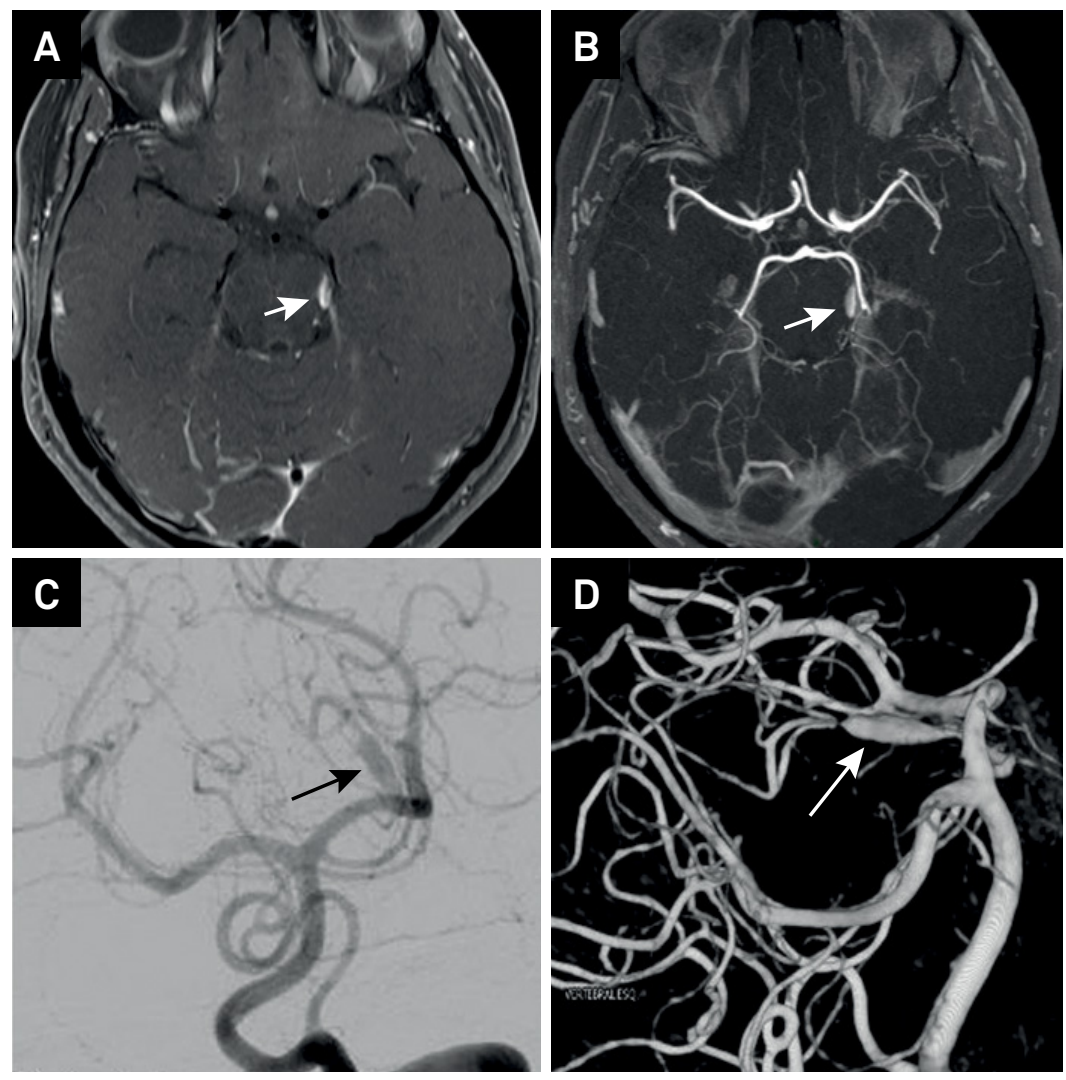

Figure 1. Axial post-contrast brain MRI (vessel wall imaging) shows abnormal asymmetric vessel wall enhancement in left superior cerebellar artery (A); axial 3D-TOF MRI angiography shows segmental ectasia in the left superior cerebellar artery (B). Digital subtraction angiogram of the left vertebral artery and 3D reconstructions confirmeda dissecting superior cerebellar artery aneurysm (lateral pontomesencephalic segment) (arrows) (C and D).

${ }^{1}$ Hospital Israelita Albert Einstein, São Paulo SP, Brasil;

${ }^{2}$ Universidade Federal de São Paulo, Departamento de Neurologia, São Paulo SP, Brasil.

Correspondence: José Luiz Pedroso; Departamento de Neurologia da UNIFESP;Av. Santa Catarina;04378-200 São Paulo SP, Brasil; E-mail:zeluizpedroso@yahoo.com.br Conflict of interest: There is no conflict of interest to declare.

Received 15 January 2017; Accepted 18 July 2017. 

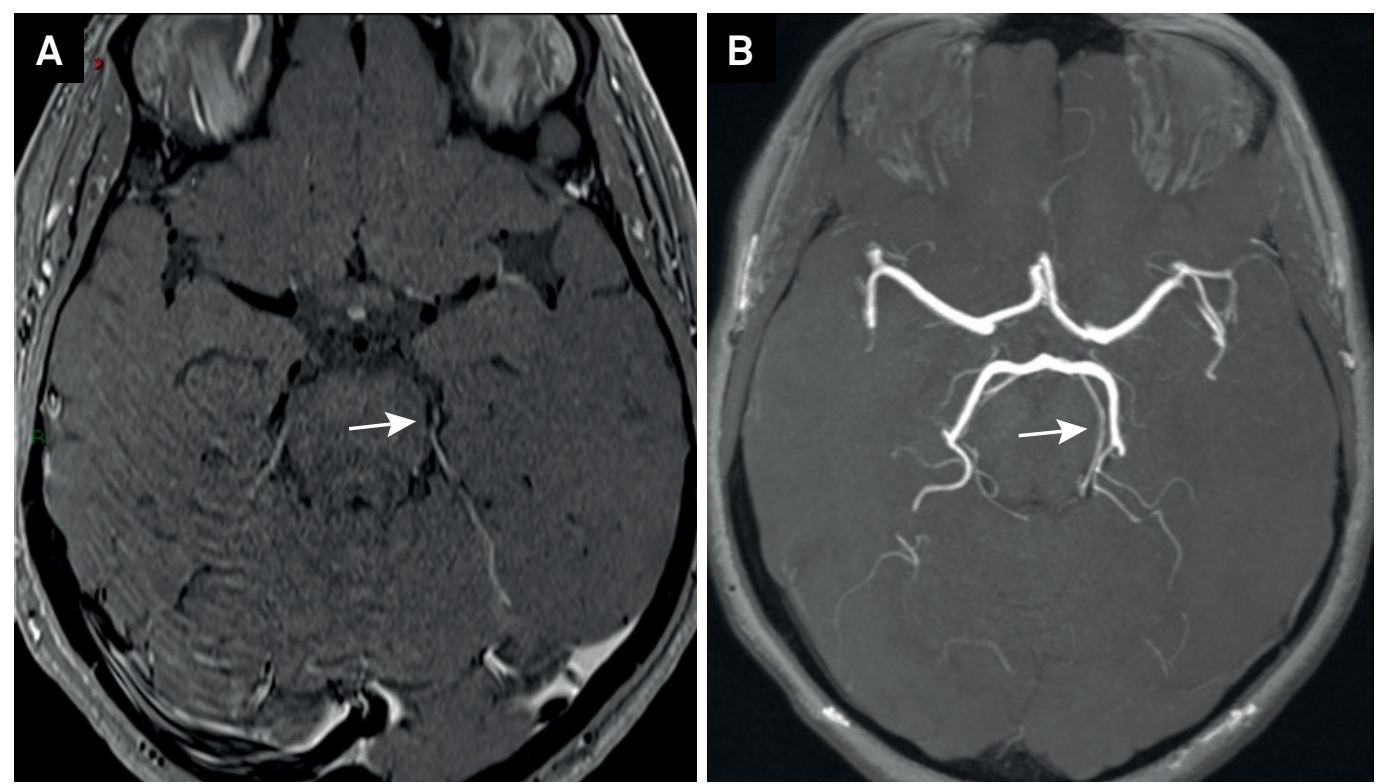

Figure 2. Six-month follow-up. Axial post-contrast brain MRI (vessel wall imaging) shows no enhancement in left superior cerebellar artery (A); axial 3D-TOF MRI angiography shows no artery aneurysm (B).

Fusiform aneurysms of the SCA related to dissection are rare ${ }^{1,2}$. Treatment strategies are usually aggressive and include: aneurysm clipping, arterial bypasses and artery oclusion $^{1,2,3}$. Our report suggests that noninvasive therapy should be considered as an option for unruptured fusiform aneurysms of the SCA related to dissection.

\section{References}

1. Lamis FC, De Paiva Neto MA, Cavalheiro S. Fusiform superior cerebell arartery aneurysm treated with STA-SCA by

passand trapping. Surg Neurol Int. 2014;5(Suppl 4):S139-42. https://doi.org/10.4103/2152-7806.134806

2. Kang IH, Malla HP, Lee SH, Park CK, Choi SK.

Revascularization as treatment of a ruptured fusiform aneurysm at the cortical segment of the superior cerebellar artery: a case report and literature review. J Neurol Surg A Cent Eur Neurosurg. 2017;78(3):302-5. https://doi.org/10.1055/s-0036-1582436

3. Li M, Wang W, Lin N, Wang J, Wang Y, Chen Z, Chen Q. Endovascular management of ruptured basilar superior cerebellar artery junction aneurysms: a series of three cases with review of literature. Int J Clin Exp Med. 2015;8(5):7627-33. 